\title{
Cycles, Arrows and Turbulence: Time Patterns in Renal Disease, a Path from Epidemiology to Personalized Medicine?
}

\author{
Jeroen P. Kooman ${ }^{a}$ Len A. Usvyat ${ }^{b}$ Marijke J.E. Dekker ${ }^{a}$ Dugan W. Maddux ${ }^{b}$ \\ Jochen G. Raimann ${ }^{c}$ Frank M. van der Sande ${ }^{a}$ Xiaoling $\mathrm{Ye}^{c}$ Yuedong Wang ${ }^{d}$ \\ Peter Kotankoc, e
}

${ }^{a}$ Maastricht University Medical Center, Maastricht, The Netherlands; ${ }^{\mathrm{b}}$ Fresenius Medical Care North America,

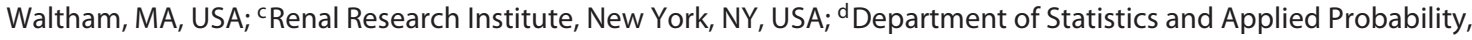

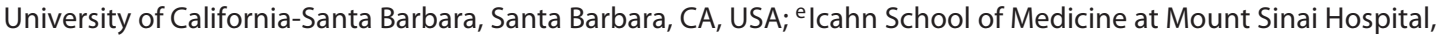
New York, NY, USA

\section{Keywords}

End-stage renal disease · Pathophysiology · Circadian .

Seasonal $\cdot$ Heart rate variability $\cdot$ Epidemiology .

Interdialytic period

\begin{abstract}
Patients with end-stage renal disease (ESRD) experience unique patterns in their lifetime, such as the start of dialysis and renal transplantation. In addition, there is also an intricate link between ESRD and biological time patterns. In terms of cyclic patterns, the circadian blood pressure (BP) rhythm can be flattened, contributing to allostatic load, whereas the circadian temperature rhythm is related to the decline in BP during hemodialysis (HD). Seasonal variations in BP and interdialytic-weight gain have been observed in ESRD patients in addition to a profound relative increase in mortality during the winter period. Moreover, nonphysiological treatment patters are imposed in HD patients, leading to an excess mortality at the end of the long interdialytic interval. Recently, new evidence has emerged on the prog-
\end{abstract}

nostic impact of trajectories of common clinical and laboratory parameters such as BP, body temperature, and serum albumin, in addition to single point in time measurements. Backward analysis of changes in cardiovascular, nutritional, and inflammatory parameters before the occurrence as hospitalization or death has shown that changes may already occur within months to even 1-2 years before the event, possibly providing a window of opportunity for earlier interventions. Disturbances in physiological variability, such as in heart rate, characterized by a loss of fractal patterns, are associated with increased mortality. In addition, an increase in random variability in different parameters such as BP and sodium is also associated with adverse outcomes. Novel techniques, based on time-dependent analysis of variability and trends and interactions of multiple physiological and laboratory parameters, for which machine-learning approaches may be necessary, are likely of help to the clinician in the future. However, upcoming research should also evaluate whether dynamic patterns observed in large epidemiological studies have relevance for the individual risk profile of the patient.

(C) 2018 The Author(s)

Published by S. Karger AG, Basel

\section{KARGER}

E-Mail karger@karger.com www.karger.com/bpu (c) 2018 The Author(s)

Published by S. Karger AG, Basel

Karger

Open access

This article is licensed under the Creative Commons AttributionNonCommercial-NoDerivatives 4.0 International License (CC BY NC-ND) (http://www.karger.com/Services/OpenAccessLicense). Usage and distribution for commercial purposes as well as any distribution of modified material requires written permission.
Jeroen P. Kooman, MD, PhD

Department of Internal Medicine, Division of Nephrology

Maastricht University Medical Center, PO Box 5800

NL-6202 AZ Maastricht (The Netherlands)

E-Mail jeroen.kooman@mumc.nl 


\section{Introduction}

Patients with renal disease experience time patterns that are different from those of healthy subjects. Chronic kidney disease $(\mathrm{CKD})$ often progresses through the course of time [1], a dynamic that may depend on the cause of renal failure [2], the presence of albuminuria [3], or other risk factors such as hypertension, fluid overload, or heart failure [1]. Moreover, the patient can experience 2 unique transitions in their life course, that is, the start of dialysis, when the patient becomes dependent for survival upon extracorporeal therapy [4], as well as renal transplantation, during which independence from dialysis is regained. Nonphysiological external time patterns are imposed especially on hemodialysis (HD) patients, most notably through the generally prescribed $4 \mathrm{~h}$ - thrice weekly schedule. Renal failure can also have a profound interaction with biological time. Biological time can be subdivided into physiological, which can in turn be cyclical or noncyclical, and nonphysiological patterns [5]. Moreover, recent evidence showed that risk factors in different domains, which usually are interpreted either in isolation or at a static point in time, can follow distinct trajectories that may be of importance for the development of future dynamic risk models. In addition, patients with end-stage renal disease (ESRD) can also experience alterations in the "miles on the clock," that is, an accelerated aging process - a topic that has been extensively covered in recent papers $[6,7]$ but not discussed in the present review.

Changes in biological time patterns are deeply connected to the pathophysiology of complications of renal disease. In this review, we discuss alterations in physiological time patterns, as well as dynamic trajectories of risk factors and the relevance of (non)-physiologic variability in patients with ESRD.

\section{Physiological Time Patterns and the Impact of Renal Disease Cyclical Time Patterns}

Cyclical rhythms have strongly preserved evolutionary roots and serve to align the organism with the changing demands of the environment [5]. The most prominent rhythms are circadian and seasonal rhythms (Fig. 1), although recently also a circaseptan (7-day) rhythm in renal sodium excretion has been discovered [8].

\section{Circadian Patterns}

Circadian rhythms allow for the adaptation of the organism to the day-night cycle and coordinate the re- sponse when it is most needed [9]. While the master regulator of circadian rhythmicity is located in the suprachiasmatic nucleus, the synchronization with peripheral oscillators, environmental and metabolic cues is essential for physiological fine tuning [10]. Peripheral clocks are also located in the kidney and regulate physiologic processes such as glomerular filtration rate and sodium excretion [10]. The circadian blood pressure (BP) rhythm is a complex phenomenon in which multiple exogenous and endogenous factors, such as the wake/sleep cycle, physical activity, the autonomic nervous system but also other neurohumoral systems, such as the renin-angiotensin and cortisol systems are involved [11-14].

A so-called non-dipping pattern in the circadian BP cycles is associated with increased left ventricular hypertrophy and worsened prognosis [15]. It is likely caused by an increased BP load or a tonic increase in sympathetic tone. Abnormalities in the circadian BP rhythm are very common in $\mathrm{CKD}$, and carry adverse prognostic significance $[5,13]$, although one study showed that this was mainly explained by common risk factors present in parallel [16].

In contrast, the circadian temperature rhythm seems to generally be intact in patients with ESRD. An interesting relationship was observed between circadian temperature changes and intradialytic hemodynamics. Declines in BP are accompanied by increases in body temperature during dialysis, which are involved in the pathogenesis of intradialytic hypotension by causing a reflex vasodilation [17]. The causes of the increase in body temperature during dialysis are partly explained by an initial response to hypovolemia through "skin isolation" due to peripheral vasoconstriction in response to ultrafiltration [18]. The importance of other factors was shown by the observation that body temperature still increased during dialysis without ultrafiltration [19]. In a study of 2004 HD patients, the strongest intradialytic increase in body temperature was observed during the morning shift, which coincided with the shift with the highest risk of intradialytic hypotension [20]. Moreover, this study confirmed the relationship between increases in core temperature and intradialytic drops in BP [20]. In the study of Sands et al. [21], the lowest incidence of intradialytic hypotension was observed during the evening shift, notably a time with the smallest increase in core temperature [20]. Admittedly, this association does not prove causality because patient selection may also be involved. Moreover, studies in healthy subjects showed that a circadian increase in body temperature was actually associated with skin vasoconstriction [22]. 
Fig. 1. Example of representative cyclical rhythms from [5].

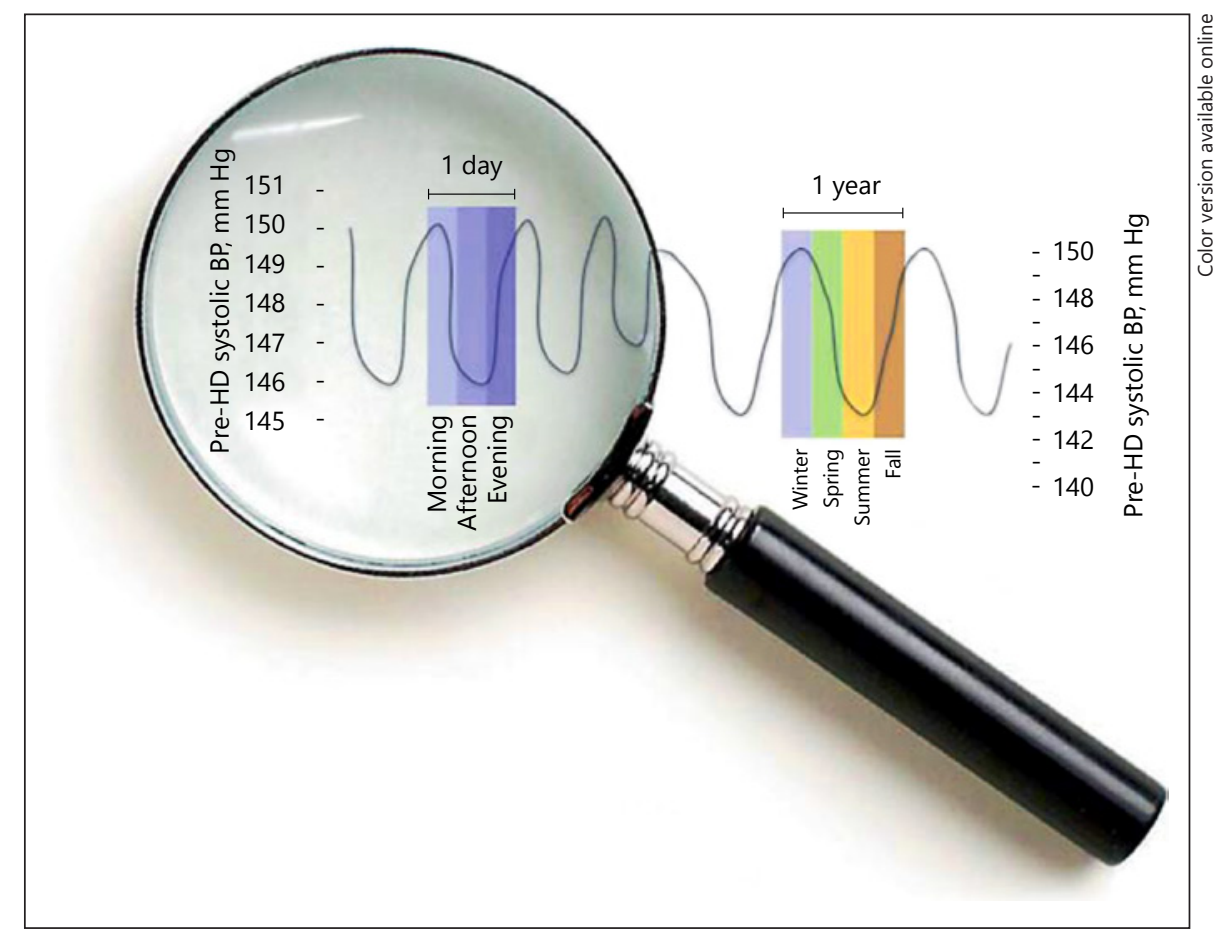

In addition to physiological rhythms, there also appears to be a circadian pattern in the risk of death in dialysis patients. In a study in 459 dialysis patients, morning death occurred $25 \%$ more often than expected [23]. While the exact reasons remain to be elucidated, the morning surge in catecholamines may be involved.

\section{Seasonal Patterns}

The most pronounced infradian rhythm is the seasonal rhythm. Seasonal patterns in BP, hospitalizations and mortality have been observed in the general population $[24,25]$. In ESRD patients, the use of electronic health records in dialysis patients has facilitated the additional study of specific patterns in laboratory and clinical parameters.

In a study in 15,056 HD patients treated in Renal Research Institute clinics, we observed clear seasonal patterns in predialysis systolic BP, predialysis body temperature, interdialytic weight gain (IDWG), and intradialytic changes in systolic BP and body temperature [26]. Predialysis systolic BP and IDWG are higher in winter months compared to summer. These findings on seasonal differences in physiological parameters are consistent with observations in nonuremic subjects [27]. However, it is likely that uremia-specific factors also play an important role in their pathogenesis. Given the strong relationship between volume overload and hypertension in dialysis pa- tients, the increases in predialysis systolic BP in winter are likely to an extent related to a larger increase in IDWG. This seasonal increase in IDWG is likely caused by increased fluid and salt intake during the winter months and additionally by reduced perspiration and fluid loss $[28,29]$. Yet, in one study in peritoneal dialysis patients, no difference in fluid state, assessed by bioimpedance, over the winter months has been observed [30]. By contrast, in another study evaluating seasonal differences in body composition, fluid overload was higher in the spring and summer period [31]. It is therefore possible that other factors also influence the difference in $\mathrm{BP}$ between the different seasons, such as sympathetic activity, vascular tone, and vitamin D levels [32-34]. Data from the Monitoring Dialysis Outcomes initiative showed comparable differences on a global level, with phase-shifted inverse patterns between the Northern and Southern hemispheres [35]. Interestingly, seasonal differences in body composition, with a higher fat mass in the winter and higher lean body mass in the summer, were observed [31].

In addition, mortality in dialysis patients was significantly and consistently different between seasons with highest mortality in the winter and lowest in the summer months, both in a US population as well as at an international level [26, 35] (Fig. 2). In the US study, mortality was especially pronounced in the winter 
Fig. 2. Seasonal variations in mortality in dialysis patients from [26].

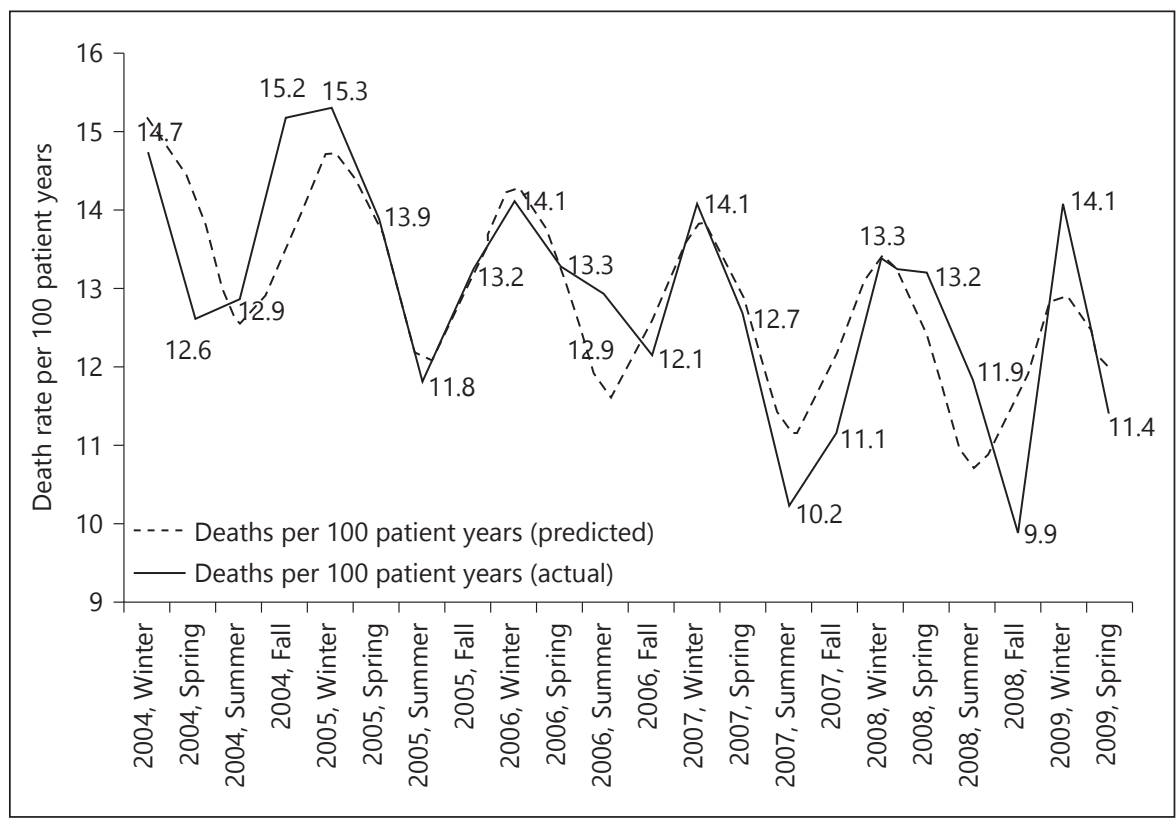

months in relatively younger patients ( $<75$ years old). This is in some contrast to a non-dialysis population where especially in the older population mortality is associated with season [24]. Possibly, the reason for the pronounced seasonal mortality differences in younger dialysis patients is explained by a higher prevalence of frailty and hence an increased susceptibility to failure of homeostatic mechanisms as compared to the general population [36-38].

Next to overall mortality, cardiovascular mortality was also significantly higher in the winter. Somewhat surprisingly, in our study, infection-related mortality did not differ between seasons even though neutrophil to lymphocyte ratio (a marker of inflammation) was higher during these months [26]. A study in 7,293 Caucasians showed that serum immunoglobulin A (IgA) levels are highest in winter. The surfaces of the gastrointestinal, respiratory, and genitourinary tracts represent major sites of potential attack by invading micro-organisms and $\operatorname{Ig} \mathrm{A}$, as the principal antibody class in the secretions that bathe these mucosal surfaces, is an important first line of defense against infection [39]. Yet, while infection-related mortality was not found to be higher in the winter months, it is possible that infections contributed to CVD mortality [40]. Although it is unclear to which extent seasonal patterns are clearly modifiable, seasonality in mortality and physiologic parameters should be taken into account in designs and analysis of epidemiologic studies.
Imposed Time Schedules: The Thrice Weekly Schedule

One of the most unphysiologic time schedules in HD patients is when weekdays are included. For societal reasons, the Sunday is generally not considered a regular day for dialysis, which means that patients are generally confined to an nonphysiological schedule of two 44-h and one 68-h interval, during which uremic toxins, electrolytes, and excess water and salt accumulate [41-43]. Various studies have shown that the long time interval is associated with an increased risk of sudden cardiac death, overall mortality, and cardiovascular mortality. Next to this, the intermittent nature of the HD treatment can impose a major circulatory stress on the body, commonly resulting in complications such as intradialytic hypotension [44-46]. Further evidence about the relevance of the interdialytic interval has emerged from a study in 66 patients by Roy-Chaudhury et al. [47] using implantable loop recorders over a 6-month period. In this study, the risk of arrhythmias, predominantly bradycardias and ventricular tachycardias, was the highest around the first dialysis session of the week and in the last $12 \mathrm{~h}$ of the long inter dialytic interval. This study corroborates results of an earlier study by Wong et al. [48] using an implantable cardiac recorder, during which the long interdialytic period and the first weekly dialysis session were found to be the periods with the highest risk for arrhythmias. Also in this study, sudden cardiac death was predominantly preceded by bradycardias.

Moreover, the long interdialytic interval imposes higher ultrafiltration rates, which are inherently associated 
with increased mortality and also with reduced perfusion of vital organs such as the brain and the heart $[49,50]$. Therefore, the long interdialytic interval may be detrimental because of aggravating fluid overload and the risk of hyperkalemia during the end of the long interdialytic interval and increase in hemodynamic stress and electrolyte imbalance during the first HD session of the week. It is therefore logical that following earlier recommendations by dialysis pioneers such as Belding Scribner, new call has been made for introduction of every other day dialysis [51]. Although in a pilot study, adoption of an every other day dialysis approach resulted, among others, in an improvement in BP control and left ventricular mass [52], it will likely have to pass many financial and practical obstacles before widespread implementation [51].

\section{The Arrow of Time}

\section{Predicting the Future: Forward Trajectories}

Given the vulnerability of the dialysis population, it is of greatest importance to identify patients at risk, particularly since timely interventions might prevent deterioration of a clinical situation before reaching a point of no return. Various outcome risk factors have been identified in ESRD, generally related to CV, nutritional, and inflammatory domains, or to abnormalities of mineral metabolism. Factors in each of these domains, such as low systolic BP, fluid overload, indicators of inflammation such as elevated levels of C-reactive protein and/or low serum albumin levels, or hyperphosphatemia have strong associations with mortality. However, the combination of risk factors may be even more powerful, especially when different dimensions are combined [53] but not always when parameters reflecting a single domain are combined [54].

Not only a combination of risk factors but also their persistence over time appears to be predictive of outcome. When studying patients stratified into subgroups based on the presence or absence of fluid overload and inflammation, additionally accounting for the change in these parameters during a 3-month period, a nearly ninefold increased risk of mortality was observed in those with a continuing, persistent presence of both risk factors [53]. In a study by Zoccali et al. [55], the highest risk was observed in patients with low systolic BP and persistent fluid overload over a 1-year period.

When looking at dynamics in risk factors, "forwardlooking" approaches starts from a certain point in time such as initiation of dialysis - and tracks patients forward in time. It has been shown that trajectories of common

Cycles, Arrows and Turbulence: Time

Patterns in Renal Disease

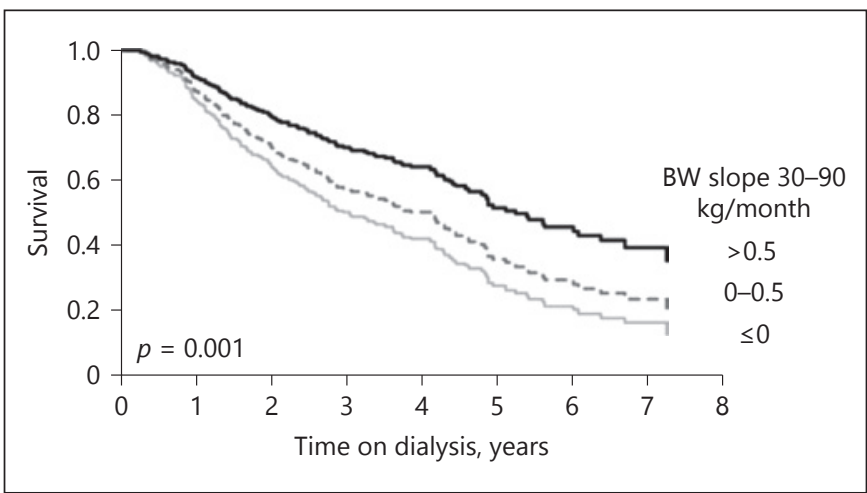

Fig. 3. Trajectory of body weight (BW) during the first year on dialysis in relation to outcome from [60].

clinical and laboratory parameters following the start of dialysis were related to increased mortality. This was true even for downward trends in serum albumin and body weight, and both upward and downward trends of predialytic systolic BP and body temperature [56-60] (Fig. 3). However, the relation between changes in systolic BP and body weight following the start of dialysis is complex. In a study by the Tassin group, a decline in BP in the first year following the start of dialysis was actually associated with an improved survival [61]. Most likely, discrepancies in the literature can be solved only by taking the interaction between both parameters and fluid status into account. Recently, also the potential relevance of trajectories in the phase preceding the start of dialysis was observed. When comparing patients who survived or did not survive the first year on dialysis, the latter group showed not only a lower systolic BP 12 months before dialysis but also a significantly larger downward trend in the year preceding the start of dialysis as compared to survivors [62] (Fig. 4).

The immediate period following the start of dialysis (90-120 days) is associated with a high mortality risk [63]. While this period is generally underrepresented in observational studies, early detection of risk factors is of greatest importance in identifying patients who need intensive medical attention. In a study in which patients were followed with weekly intervals during the first year on dialysis, absolute mortality was highest during the first 3 months of dialysis, but the relative risk associated with low systolic BP persisted throughout the entire year [64].

\section{Learning from the Past: Backward Analysis}

Backward-looking approaches select a common end point for all patients, such as hospitalization or death and trace time backwards from this end point. The trajectory 
Fig. 4. Trajectories of SBP before the start of dialysis in patients who survived, or did not survive the first year on dialysis from [62]. SBP, systolic blood pressure; ESRD, end-stage renal disease.

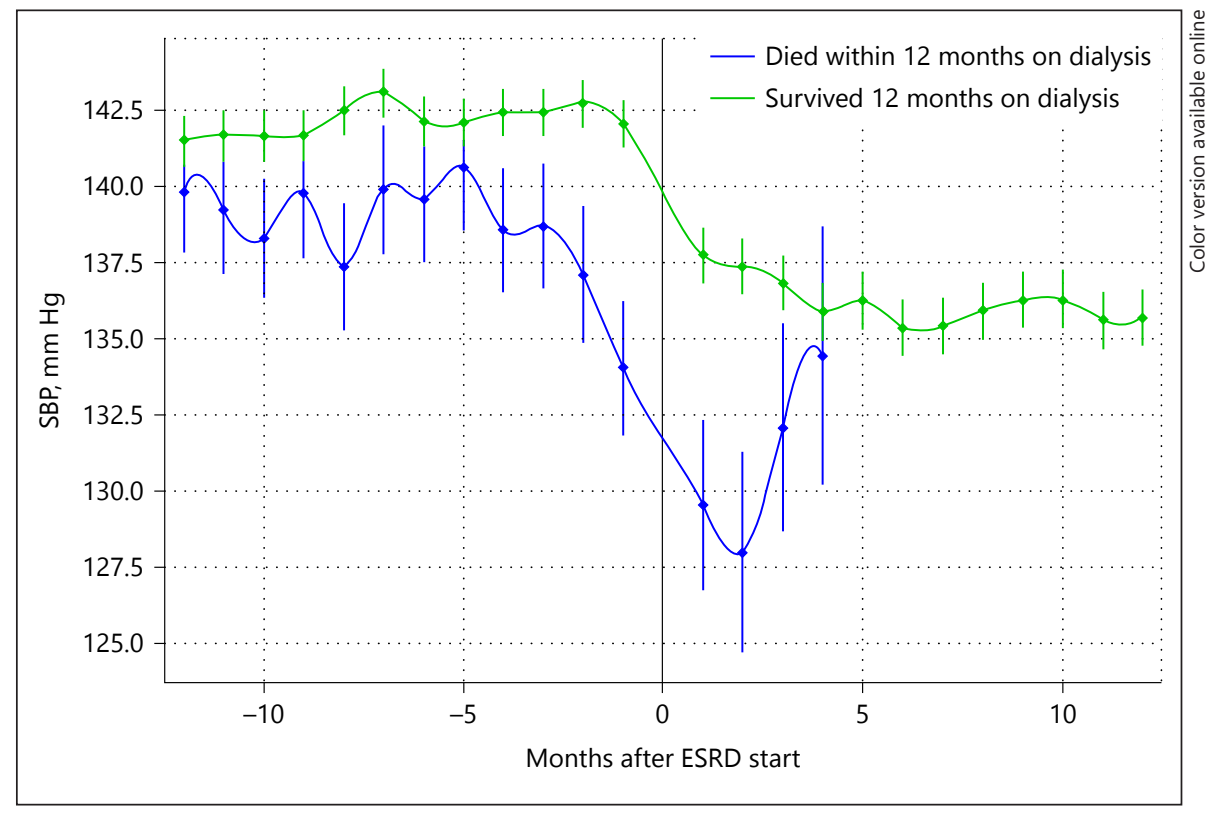

of patient parameters before this event can be estimated using statistical techniques such as (smoothing or penalized) spline analysis $[65,66]$. This approach demonstrates what happens to patients' parameters before an event of interest on a population level [67]. This could aid both in increasing the understanding the pathophysiology of complications of renal disease, and for the further refinement in the design of predictive risk models and flagging of early warning signals. Using backward analysis, a decline in a composite score of nutritional parameters (albumin, serum phosphate, serum creatinine, equilibrated normalized protein catabolic rate, and IDWG) was observed 1-2 months before hospitalization [68]. In other studies, important variables such as systolic BP and serum albumin were shown to decline, whereas C-reactive protein levels or the neutrophil-tolymphocyte ratio increased before death and/or hospitalization. Importantly, some of these changes already occurred until up to 1 year before the event, which could provide a "window of opportunity" for potential interventions [69, 70] (Fig. 5). Underlying causes of these trends need to be addressed in more detail in future studies and are they are likely to be multifactorial. Probably, as discussed later in more detail in this review, in addition to the direct consequences of the underlying illness, such as loss of appetite resulting in malnutrition, malfunction of physiological control systems or adaptations of control systems to an unfavorable environment are involved [71].

\section{Do We Have Evidence That Longitudinal Data Improve Outcome Prediction Models?}

Although, as discussed previously, longitudinal data appear to add prognostic information in, its use in prediction models in ESRD is limited at present. The most widely used prognostic models, such as the Cohen, Floege, and REIN models rely on single point-in-time measurements [72-74]. A recent systematic review of 16 risk prediction models in ESRD patients showed c-statistics between 0.71 and 0.75 with external validation [75]. We recently showed that the inclusion of the dynamics of nutritional score in a Cox model improved the predictive outcome for mortality next to a single point in time measurement but did not yet formally validate this model in an external cohort [76]. There are various proposed statistical techniques to analyze longitudinal data in relation to survival, based on joint modeling approaches that have been discussed in recent reviews, which might be used for the construction of future risk prediction models including dynamics of important variables [77, 78]. Recently, a dynamic prediction model based on "latest-available-measurements" in patients with CKD outperformed a model based on values derived during baseline visits in the prediction of ESRD $[79,80]$. In another example, cardiovascular risk prediction in the general population using machine learning and "deep learning" accessing longitudinal data from electronic health records outperformed ACC/AHA Pooled Cohort Risk Equations for 10-year cardiovascular disease (c-statistic $0.78-0.79$ vs. 0.73) [119]. 
Fig. 5. Dynamics in hospitalizations and selected clinical and laboratory parameters before death from [69]. SBP, systolic blood pressure; NLR, neutrophil to lymphocyte ratio.

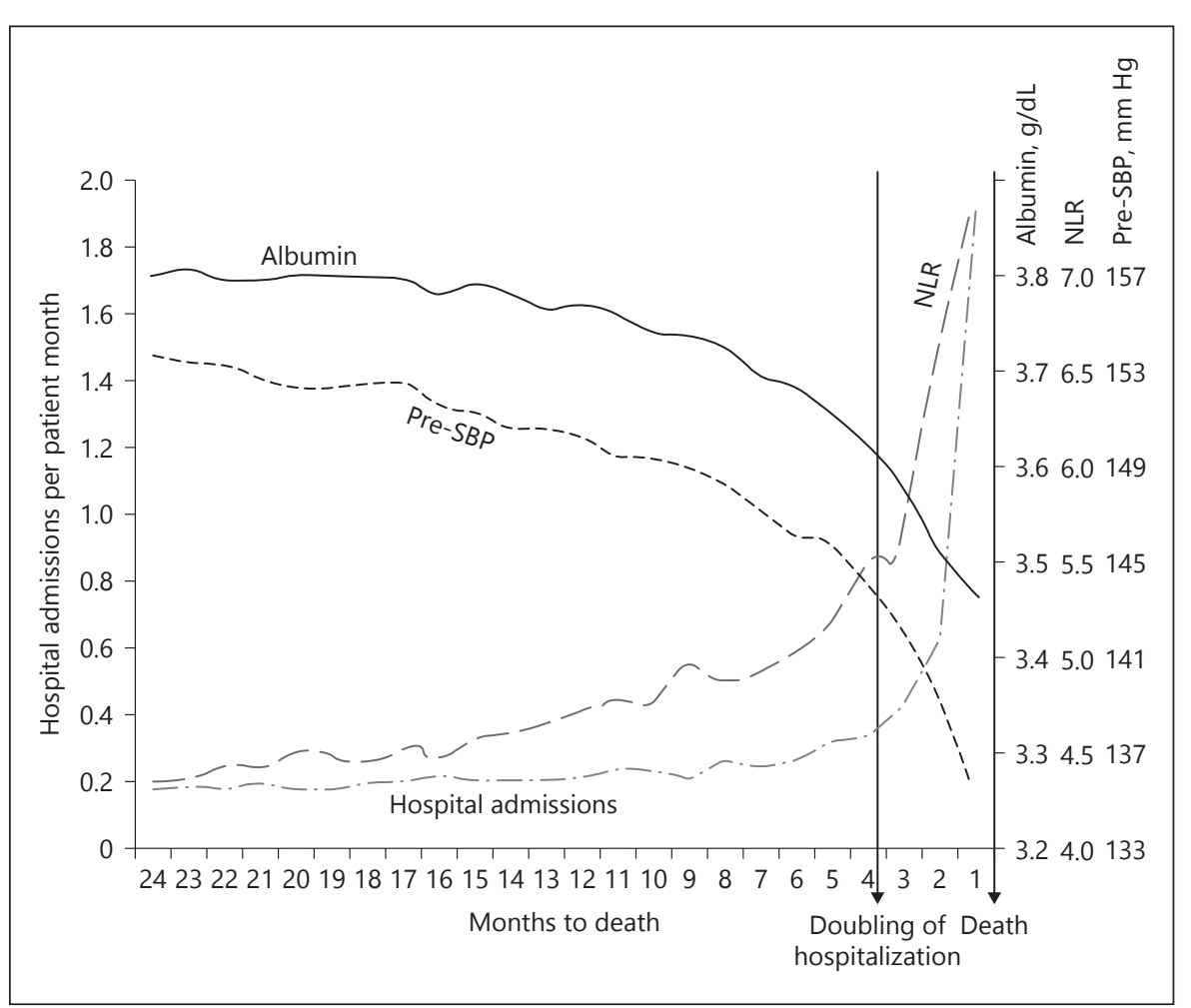

One caveat of longitudinal risk prediction models in ESRD patients could be that the predictive value of parameters might partly depend on the interaction with others. As an example, low systolic BP was associated with increased mortality and patients with fluid depletion or fluid overload but an improved survival in normovolemic patients [81]. In addition, a decrease in serum phosphate may be associated with improved outcomes in wellnourished patients but may be predictive of mortality in patients with progressive signs of malnutrition [76]. Possibly, machine-learning approaches, which have preliminarily shown to be successful in outcome prediction for metastatic cancer [82], may aid in the construction of dynamic risk prediction models in ESRD. However, several caveats with machine-learning approaches have also been mentioned, such as the risk for overfitting and the high sensitivity of nonlinear systems to initial conditions ("butterfly" effect) [83].

\section{Turbulent Times}

\section{Physiological Variability}

Noncyclical variation is also an essential prerequisite of life [84]. While relative constancy is desirable for certain parameters, especially those involved in cellular in- tegrity and control such as calcium, $\mathrm{pH}$, glucose, temperature, and osmolality [85], variability in other physiological parameters is essential for survival [86]. An obvious example is the heart rate response to hypovolemia, contributing to stability in BP despite internal or external disturbances. Under stable conditions in health, heart rate is not entirely regular [87]. Physiological heart rate variability (HRV) indicates an adequate connection between the heart and autonomous nervous system, as well as a coupling between 2 important biological oscillators, that is, respiration and heart rate $[87,88]$.

Physiological variability shows either a cyclical (e.g., circadian) or fractal pattern. The latter is characterized by a $1 / f(f=$ frequency) pattern [88-90]. The $1 / f$ pattern, in which the amplitude of the variations is inversely related to its frequency, remains similar over different time scales. 1/f patterns have been described for a variety of physiological processes, including human gait, HRV, and brain activity. This pattern is a representative of the complexity of a system, and loss of $1 / \mathrm{f}$ patterns is believed to be an indicator of a loss or dysfunction of the connection between coupled physiological systems (such as the circulatory and respiratory system in case of HRV). This leads to a disturbance in information transfer between systems due to loss of temporal synchronization [89], which may lead to impairment in homeostasis [85]. 
Fig. 6. Example of a simple linear control circuit from [71].

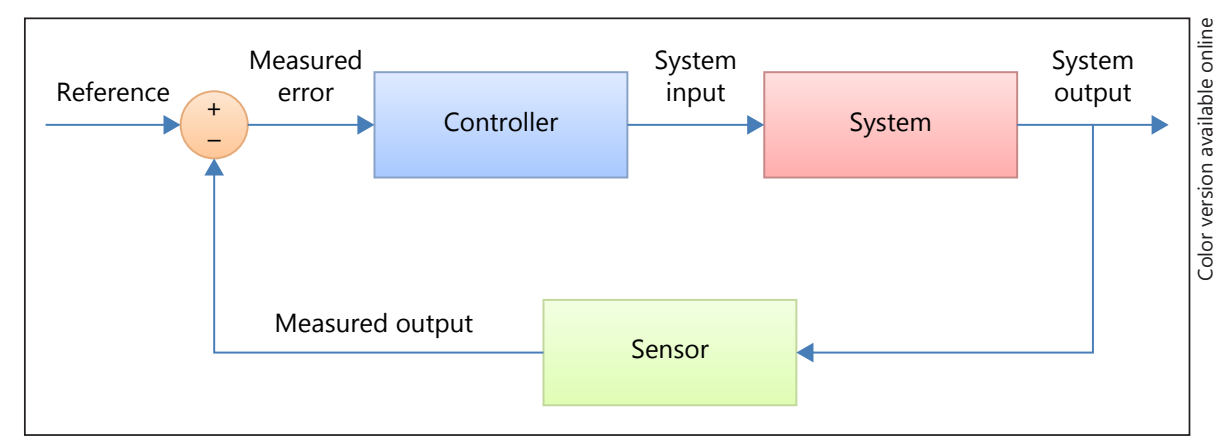

Different disease states, including ESRD, are associated with alterations in HRV, related to the autonomic dysfunction. Disturbances in physiological HRV are associated with an adverse prognosis [91]. In a study of 383 HD patients, a standard deviation of RR intervals below $75 \mathrm{~ms}$ was associated with increased cardiovascular and all-cause mortality [92]. Recently, nonlinear analyses of $\mathrm{HRV}$ in dialysis patents have also been studied in relation to outcome. Interestingly, a reduction of the fractal component of HRV was associated with an increased mortality in a study in $281 \mathrm{HD}$ patients [93]. The relation between a reduced HRV and outcome may be due to an increased risk for sudden cardiac death [94]. The mechanisms behind reduced HRV in dialysis patients are likely multifactorial and include among others autonomous neuropathy leading to baroreflex arc dysfunction [95]. However, fluid overload, which is an important independent predictor of outcome [53] but also amendable to therapeutic intervention [96], is also related to reduced HRV [97].

\section{Nonphysiological Variability}

Next to physiological variability, which adapts the organism to environmental changes or serves to align and fine tune different organ systems $[87,90]$, and is as such a sign of health, nonphysiological variability is related to adverse outcomes. In contrast to physiological (fractal) variability, which contains relevant information for homeostatic functioning, nonphysiological variability is related to adverse outcomes. Most studies in this subject in ESRD have been performed with BP as the physiologic parameter. The relation between outcome and an increase in BP variability, which is usually expressed by SD (with or without correction for the mean, or as SD of the residuals) [98-100] has been observed at different time scales. Both an increased BP variability of predialytic, as well as intradialytic systolic BP were related to increased mortality [100-102]. Possibly, this increased variability is due to a disturbance in baroreceptor control mechanism or to structural cardiovascular abnormalities such as an increase in arterial stiffness [98]. In nonuremic patients, Webb and Rothwell [103] found that in patients who had recently experienced stroke, an increased BP variability was related to reduced HRV and an increase in arterial stiffness. In ESRD patients, ultrafiltration volume and ultrafiltration rate were predictors of intra-dialytic BP variability [104]. In non-renal patients, BP variability was associated with increased brain natriuretic peptide and atrial natriuretic peptide levels suggesting also a role for fluid overload in the pathogenesis [105]. The causes of BP variability may be conceptually described using control theory. In a feedback system, disturbances of the outcome signal from the set point might occur either because of damage of sensor system, when perturbations that are too severe for the system to cope with, or when the gain ("sensitivity") of the feedback system or the effectiveness of effector systems is disturbed, leading to wider, apparently "random" variability around the set point [85] (Fig. 6). For BP variability, relevant sensor systems include the baroreceptors, perturbations may include fluid status, whereas disturbed effector systems may include the arterial buffering system, as well as the baroreceptor and cardiac function.

The prognostic value of nonphysiologic variability does not seem to be limited to BP. In addition, we also recently observed a relation between variability of predialytic plasma sodium levels and mortality (Ye et al., unpubl. data), suggesting that increased variability may be a generic phenomenon, reflecting impaired homeostatic regulatory mechanisms. However, until now, it has not been investigated whether variability of different parameters, such as BP and serum sodium, are coupled. However, a recent study showed a relation between changes in plasma sodium levels and BP [106]. More research is needed to look at the relation between variability in different parameters at different time scales, and their im- 
Fig. 7. Change in nutritional score before and after subsequent hospitalizations from [75].

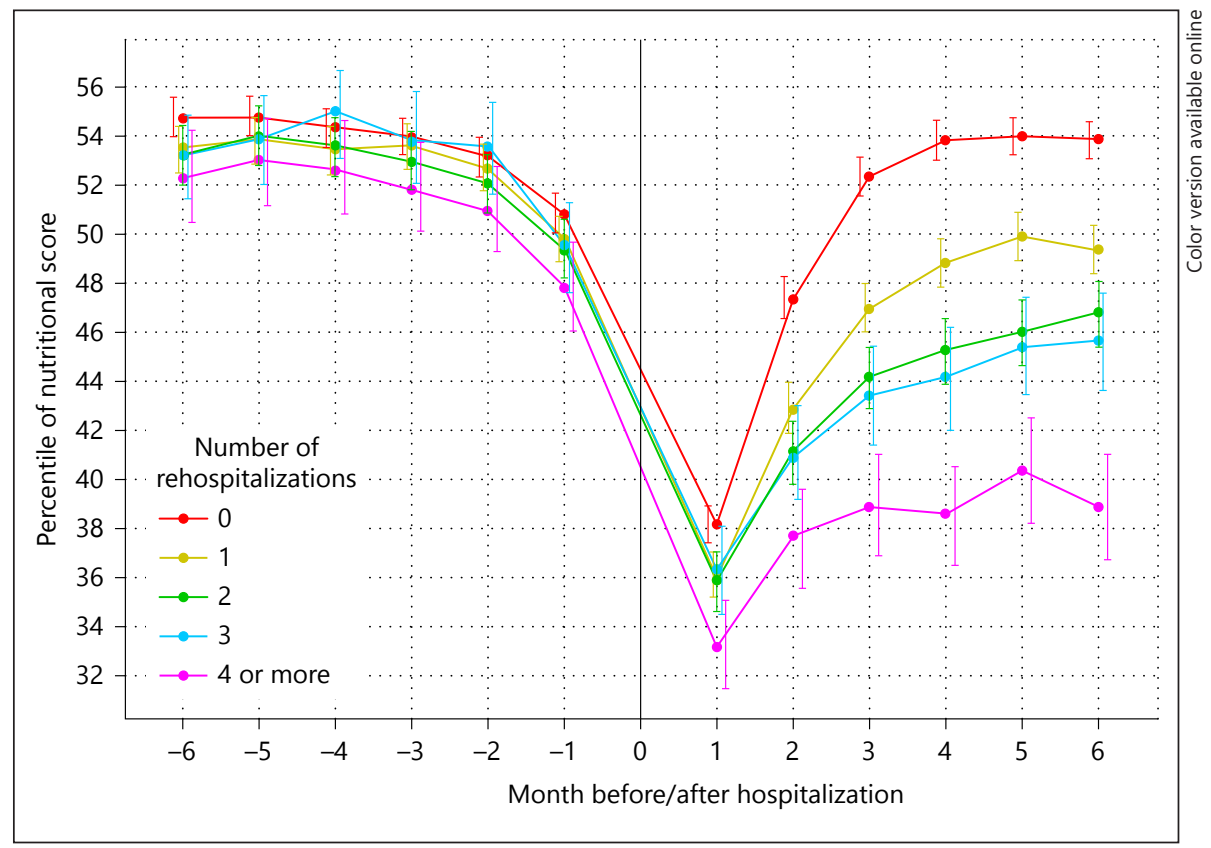

pact on prognosis, and to further explore the relation between variability and phenotypical alterations, such as cardiac failure or frailty [107].

\section{Critical Transitions}

Research from past decades has shown the importance of nonlinear variations in predicting critical transitions reflecting system breakdown [108]. In various systems that are characterized by a loss of resilience, random variability increases before a transition point to an alternative state is reached. This phenomenon has been observed in widely ranging phenomena from ecosystems to epileptic attacks $[109,110]$. In addition, the recovery time after stressors is delayed, which may be explained by an impaired efficacy or power of control or effector systems. Systems characterized by a loss of resilience are characterized by rapid transition to an alternative state after minor disturbances [108], which shows interesting parallels with the rapid loss of homeostatic functioning in patients with the frailty syndrome [111]. The study toward critical transitions in ESRD is still in its infancy. However, a recent study showed longer recovery times in a multidimensional nutritional score after subsequent rehospitalizations [68] (Fig. 7). Whether the increase in random variability discussed in the previous paragraph indeed precedes a critical transition has not been studied yet in the ESRD population. However, in a recent study, we showed that an incremental increase in variability in systolic BP between 2 different time points was predictive of mortality (Dekker et al., unpubl. data). More studies of the relationship between variability in various domains over different time scales, critical transitions and outcome are needed to estimate the potential importance of these temporal trends for individual patients.

\section{Premature Aging and Alterations in Time Patterns}

In previous papers, causes and consequences of a premature aging in ESRD were extensively discussed $[6,7$, $112,113]$. Next to an increase in mortality as compared to age-matched controls, this process is phenotypically characterized by structural abnormalities in various organ systems, such as cardiac hypertrophy, an increase in arterial stiffness, osteopenia, loss of lean tissue mass and a high prevalence of the frailty syndrome even in young dialysis patients $[6,36]$. At a (sub)cellular level, telomere attrition, mitochondrial dysfunction with impaired cellular energy metabolism, as well as inhibition of anabolic and stimulation of catabolic processes are observed, as well as cellular transdifferentiation $[6,7,114]$. Causally, next to lifestyle and (epi)genetic factors, an increase in allostatic load (e.g., caused by inflammation), an increase in pro-aging factors such as phosphate, and an impairment of anti-aging mechanisms (e.g., Klotho) may be involved $[6,112,113]$ (Fig. 8). Disturbed time cycles can theoretically also contribute to this process, for example, by an increase in allostatic load through a 
Fig. 8. Potential determinants of changes in time patterns in end-stage renal disease (ESRD).

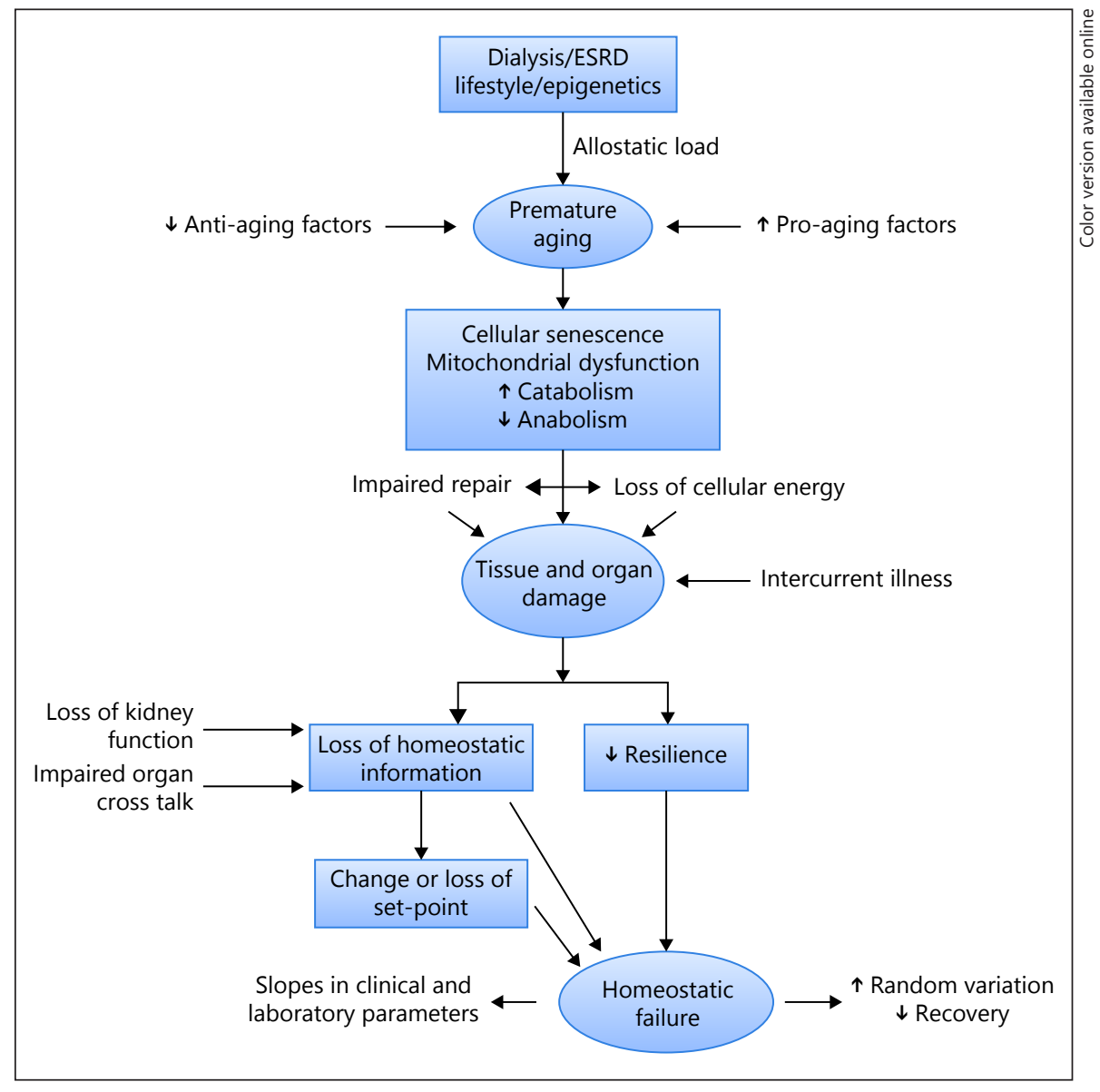

\section{Epidemiological Data and Personalized Medicine}

The goal of personalized medicine is to provide a granular classification of patients into subpopulations that differ in their susceptibility to a particular disease, in the biology or prognosis of those diseases they may develop, or in their response to a specific treatment. While technologies such as genomics, proteomics, metabolomics, and transcriptomics are fundamentally important to precision medicine, the patient-level analysis of temporal trajectories may provide further insights well beyond the "static" pattern. Possibly, future integration of panomic and temporal analysis will provide novel means to personalized medicine, which may be aided by machinelearning approaches [115]. Nevertheless, machine-learning approaches, which essentially rely on theory-free associations in the data [83], may be followed by even "smarter" artificial intelligence approaches, based on causal mediation, and may improve their usefulness in the clinical decision process [116]. Also, the clinical validity of future models should be expressed in terms of out- 
come prediction, with use of, for example, advanced-care planning, or early detection of potentially intervenable disorders, which may escape the clinician's eye, thus providing a so-called window of opportunity. The authors however fully agree with the statement of Chen and Asch [83] that future models based on artificial intelligence should always be used as an aid to, but not as a replacement of the clinical decision process. Moreover, it should be noted that complicated statistical approaches do not necessarily outperform more simple models [117]. However, methods based on multiple longitudinal covariates, which are at present at a developmental state [118], have the potential to further improve outcome prediction. Future research on statistical and computational methods for joint modeling multivariate longitudinal variables and survival time with massive data is needed.

\section{Conclusion}

There is a pronounced effect of ESRD on cyclical physiological time patterns, as shown by abnormalities in the circadian BP rhythm. On the other hand, seasonal pat- terns have a strong relation with variations in various risk factors, but also mortality in ESRD patients. Longitudinal trajectories of risk factors have an additive predictive power that is superior to single point-in-time measurements and may improve the calculation of the risk profile and provide a "window of opportunity" for more timely interventions. In addition, analysis of backward patterns from an event such as hospitalization or death may further refine these models, although it should be evaluated in future trials whether these epidemiological patterns have relevance for individual patients. Unlike physiological variability, characterized by a fractal patterns, an increase in apparently random variability in parameters such as $\mathrm{BP}$ is also associated with a higher risk of mortality. Whether this increase in variability is a general reflection of impaired homeostasis, and/or related to phenotypical abnormalities such as frailty should be evaluated in future trials.

\section{Disclosure Statement}

P.K. and L.A.U. hold stock in Fresenius Medical Care. All other authors do not have any potential financial conflicts of interest to declare.

\section{References}

1 Gallar P, Ortega O, Carreno A, Vigil A: Rate of decline in residual renal fuction is equal in CAPD and automated peritoneal dialysis patients. Perit Dial Int 2000;20:803-805.

2 Abe M, Okada K, Maruyama N, Takashima $\mathrm{H}$, Oikawa O, Soma M: Comparison of clinical trajectories before initiation of renal replacement therapy between diabetic nephropathy and nephrosclerosis on the KDIGO guidelines heat map. J Diabetes Res 2016; 2016:5374746.

3 Ozyilmaz A, de Jong PE, Bakker SJ, Visser ST, Thio C, Gansevoort RT, et al: Screening for elevated albuminuria and subsequently hypertension identifies subjects in which treatment may be warranted to prevent renal function decline. Nephrol Dial Transplant 2017; 32:200-208.

4 Broers NJ, Cuijpers AC, van der Sande FM, Leunissen KM, Kooman JP: The first year on haemodialysis: a critical transition. Clin Kidney J 2015;8:271-277.

5 Kooman JP, Usvyat L, van der Sande FM, Thijssen S, Levin N, Leunissen KM, et al: "Time and time again": oscillatory and longitudinal time patterns in dialysis patients. Kidney Blood Press Res 2012;35:534-548.

6 Kooman JP, Kotanko P, Schols AM, Shiels PG, Stenvinkel P: Chronic kidney disease and premature ageing. Nat Rev Nephrol 2014;10: 732-742.
7 Stenvinkel P, Larsson TE: Chronic kidney disease: a clinical model of premature aging. Am J Kidney Dis 2013;62:339-351.

8 Rakova N, Juttner K, Dahlmann A, Schroder A, Linz P, Kopp C, et al: Long-term space flight simulation reveals infradian rhythmicity in human $\mathrm{Na}(+)$ balance. Cell Metab 2013; 17:125-131.

9 Labrecque N, Cermakian N: Circadian clocks in the immune system. J Biol Rhythms 2015; 30:277-290.

10 Solocinski K, Gumz ML: The circadian clock in the regulation of renal rhythms. J Biol Rhythms 2015;30:470-486.

11 Smolensky MH, Hermida RC, Portaluppi F: Circadian mechanisms of 24-hour blood pressure regulation and patterning. Sleep Med Rev 2017;33:4-16.

12 Agarwal R, Light RP: Physical activity is a determinant of circadian blood pressure variation in chronic kidney disease. Am J Nephrol 2010;31:15-23.

13 Liu M, Takahashi H, Morita Y, Maruyama S, Mizuno M, Yuzawa Y, et al: Non-dipping is a potent predictor of cardiovascular mortality and is associated with autonomic dysfunction in haemodialysis patients. Nephrol Dial Transplant 2003;18: 563-569.

14 Velasquez MT, Beddhu S, Nobakht E, Rahman M, Raj DS: Ambulatory blood pressure in chronic kidney disease: ready for prime time? Kidney Int Rep 2016;1:94104.

15 Rahman M, Griffin V, Heyka R, Hoit B: Diurnal variation of blood pressure; reproducibility and association with left ventricular hypertrophy in hemodialysis patients. Blood Press Monit 2005;10:25-32.

16 Agarwal R, Kariyanna SS, Light RP: Prognostic value of circadian blood pressure variation in chronic kidney disease. Am J Nephrol 2009;30:547-553.

17 Rowell LB: Reflex control of the cutaneous vasculature. J Invest Dermatol 1977;69:154166.

18 Schneditz D, Rosales L, Kaufman AM, Kaysen G, Levin NW: Heat accumulation with relative blood volume decrease. Am J Kidney Dis 2002;40:777-782.

19 van der Sande FM, Rosales LM, Brener Z, Kooman JP, Kuhlmann M, Handelman G, et al: Effect of ultrafiltration on thermal variables, skin temperature, skin blood flow, and energy expenditure during ultrapure hemodialysis. J Am Soc Nephrol 2005;16:18241831.

20 Usvyat LA, Kotanko P, van der Sande FM, Kooman JP, Carter M, Leunissen KM, et al: Circadian variations in body temperature during dialysis. Nephrol Dial Transplant 2012;27:1139-1144. 
21 Sands JJ, Usvyat LA, Sullivan T, Zabetakis P, Kotanko P, Maddux FW, et al., (eds): Intradialytic Hypotension (IH): Variation in Dialysis Facilities Annual Dialysis Conference. Seattle, 2013.

22 Raymann RJ, Swaab DF, Van Someren EJ: Cutaneous warming promotes sleep onset. Am J Physiol Regul Integr Comp Physiol 2005;288:R1589-R1597.

23 Tisler A, Logan AG, Akocsi K, Tornoci L, Kiss I: Circadian variation of death in hemodialysis patients. Am J Kidney Dis 2008;51:53-61.

24 Cold exposure and winter mortality from ischaemic heart disease, cerebrovascular disease, respiratory disease, and all causes in warm and cold regions of Europe. The Eurowinter Group. Lancet 1997;349:1341-1346.

25 Modesti PA, Morabito M, Massetti L, Rapi S, Orlandini S, Mancia G, et al: Seasonal blood pressure changes: an independent relationship with temperature and daylight hours. Hypertension 2013;61:908-914.

26 Usvyat LA, Carter M, Thijssen S, Kooman JP, van der Sande FM, Zabetakis P, et al: Seasonal variations in mortality, clinical, and laboratory parameters in hemodialysis patients: a 5-year cohort study. Clin J Am Soc Nephrol 2012;7:108-115.

27 Alperovitch A, Lacombe JM, Hanon O, Dartigues JF, Ritchie K, Ducimetiere P, et al: Relationship between blood pressure and outdoor temperature in a large sample of elderly individuals: the three-city study. Arch Intern Med 2009;169:75-80.

28 Argiles A, Mourad G, Mion C: Seasonal changes in blood pressure in patients with end-stage renal disease treated with hemodialysis. N Engl J Med 1998;339:1364-1370.

29 Sposito M, Nieto FJ, Ventura JE: Seasonal variations of blood pressure and overhydration in patients on chronic hemodialysis. Am J Kidney Dis 2000;35:812-818.

30 Cheng LT, Jiang HY, Tang LJ, Wang T: Seasonal variation in blood pressure of patients on continuous ambulatory peritoneal dialysis. Blood Purif 2006;24:499-507.

31 Broers NJ, Usvyat LA, Marcelli D, Bayh I, Scatizzi L, Canaud B, et al: Season affects body composition and estimation of fluid overload in haemodialysis patients: variations in body composition; a survey from the European MONDO database. Nephrol Dial Transplant 2015;30:676-681.

32 Argiles A, Lorho R, Servel MF, Couret I, Chong G, Mourad G: Blood pressure is correlated with vitamin $\mathrm{d}(3)$ serum levels in dialysis patients. Blood Purif 2002;20:370375.

33 Cheung AK, Yan G, Greene T, Daugirdas JT, Dwyer JT, Levin NW, et al: Seasonal variations in clinical and laboratory variables among chronic hemodialysis patients. J Am Soc Nephrol 2002;13:2345-2352.

34 van der Sande FM, Kooman JP, Leunissen KM: Clinical implications of seasonal variations in hemodialysis patients. Blood Purif 2008;26:193-195.
35 Guinsburg AM, Usvyat LA, Etter M, Xu X, Thijssen S, Marcelli D, et al: Seasonal variations in mortality and clinical indicators in international hemodialysis populations from the MONDO registry. BMC Nephrol 2015;16: 139.

36 Johansen KL, Chertow GM, Jin C, Kutner NG: Significance of frailty among dialysis patients. J Am Soc Nephrol 2007;18:2960-2967.

37 Kooman JP, Cornelis T, van der Sande FM, Leunissen KM: Renal replacement therapy in geriatric end-stage renal disease patients: a clinical approach. Blood Purif 2012;33:171176.

38 Lang PO, Michel JP, Zekry D: Frailty syndrome: a transitional state in a dynamic process. Gerontology 2009;55:539-549.

39 Weber-Mzell D, Kotanko P, Hauer AC, Goriup $\mathrm{U}$, Haas J, Lanner N, et al: Gender, age and seasonal effects on IgA deficiency: a study of 7293 Caucasians. Eur J Clin Invest 2004;34 224-228.

40 Dalrymple LS, Mohammed SM, Mu Y, Johansen KL, Chertow GM, Grimes B, et al: Risk of cardiovascular events after infection-related hospitalizations in older patients on dialysis. Clin J Am Soc Nephrol 2011;6:1708-1713.

41 Kjellstrand CM, Evans RL, Petersen RJ, Shideman JR, Von Hartitzsch B, Buselmeier TJ: The "unphysiology" of dialysis: a major cause of dialysis side effects? Hemodial Int 2004;8:2429.

42 Stockinger J, Ribitsch W, Schneditz D: Volume excess in chronic haemodialysis patients-effects of treatment frequency and treatment spacing. Nephrol Dial Transplant 2013;28:170-175.

43 Georgianos PI, Sarafidis PA, Sinha AD, Agarwal R: Adverse effects of conventional thriceweekly hemodialysis: is it time to avoid 3-day interdialytic intervals? Am J Nephrol 2015;41: 400-408.

44 Rhee CM, Kalantar-Zadeh K: Implications of the long interdialytic gap: a problem of excess accumulation vs. excess removal? Kidney Int 2015;88:442-444

45 Foley RN, Gilbertson DT, Murray T, Collins AJ: Long interdialytic interval and mortality among patients receiving hemodialysis. N Engl J Med 2011;365:1099-1107.

46 van der Sande FM, Dekker MJ, Leunissen KML, Kooman JP: Novel insights into the pathogenesis and prevention of intradialytic hypotension. Blood Purif 2018;45:230-235.

47 Roy-Chaudhury P, Tumlin JA, Koplan BA, Costea AI, Kher V, Williamson D, et al: Primary outcomes of the Monitoring in Dialysis study indicate that clinically significant arrhythmias are common in hemodialysis patients and related to dialytic cycle. Kidney Int 2018:93:941-951.

48 Wong MC, Kalman JM, Pedagogos E, Toussaint N, Vohra JK, Sparks PB, et al: Temporal distribution of arrhythmic events in chronic kidney disease: highest incidence in the long interdialytic period. Heart Rhythm 2015;12: 2047-2055.
49 Buchanan C, Mohammed A, Cox E, Kohler K Canaud B, Taal MW, et al: Intradialytic cardiac magnetic resonance imaging to assess cardiovascular responses in a short-term trial of hemodiafiltration and hemodialysis. J Am Soc Nephrol 2017;28:1269-1277.

50 Polinder-Bos HA, Garcia DV, Kuipers J, Elting JWJ, Aries MJH, Krijnen WP, et al: Hemodialysis induces an acute decline in cerebral blood flow in elderly patients. J Am Soc Nephrol 2018;29:1317-1325.

51 Gul A, Miskulin DC, Harford A, Zager P: Incenter hemodialysis: time for a paradigm shift. J Am Soc Nephrol 2018;29:2452-2454.

52 Katopodis KP, Dounousi E, Challa A, Pappas K, Kalaitzidis R, Siamopoulos KC: Switch from conventional to every other day hemodialysis: a comparison pilot study. ASAIO J 2009;55:41-46.

53 Dekker MJ, Marcelli D, Canaud BJ, Carioni P, Wang Y, Grassmann A, et al: Impact of fluid status and inflammation and their interaction on survival: a study in an international hemodialysis patient cohort. Kidney Int 2017;91: 1214-1223.

54 de Roij van Zuijdewijn CL, ter Wee PM, Chapdelaine I, Bots ML, Blankestijn PJ, van den Dorpel MA, et al: A comparison of 8 nutritionrelated tests to predict mortality in hemodialysis patients. J Ren Nutr 2015;25:412-419.

55 Zoccali C, Moissl U, Chazot C, Mallamaci F, Tripepi G, Arkossy O, et al: Chronic fluid overload and mortality in ESRD. J Am Soc Nephrol 2017;28:2491-2497.

56 Raimann JG, Usvyat LA, Thijssen S, Kotanko P, Rogus J, Lacson E Jr, et al: Blood pressure stability in hemodialysis patients confers a survival advantage: results from a large retrospective cohort study. Kidney Int 2012;81:548-558.

57 Sipahioglu MH, Usvyat L, Liu L, Abbas SR, Raimann JG, Rosales L, et al: Early systolic blood pressure changes in incident hemodialysis patients are associated with mortality in the first year. Kidney Blood Press Res 2012;35: 663-670.

58 Chiu PF, Tsai CC, Wu CL, Yang TY, Liou HH, Chen HL, et al: Trajectories of serum albumin predict survival of peritoneal dialysis patients: a 15-year follow-up study. Medicine (Baltimore) 2016;95:e3202.

59 Khoshhali M, Kazemi I, Hosseini SM, Seirafian S: Relationship between trajectories of serum albumin levels and technique failure according to diabetic status in peritoneal dialysis patients: a joint modeling approach Kidney Res Clin Pract 2017;36:182-191.

60 Duranton F, Duny Y, Szwarc I, Deleuze S, Rouanet C, Selcer I, et al: Early changes in body weight and blood pressure are associated with mortality in incident dialysis patients. Clin Kidney J 2016;9:287-294.

61 Chazot C, Vo-Van C, Deleaval P, Lorriaux C, Hurot JM, Mayor B, et al: Predialysis systolic blood pressure evolution in incident hemodialysis patients: effects of the dry weight method and prognostic value. Blood Purif 2012;33: 275-283. 
62 Maddux DW, Usvyat LA, Ketchersid T, Jiao Y, Blanchard TC, Kotanko P, et al: Clinical parameters before and after the transition to dialysis. Hemodial Int 2018;22:235-244.

63 Foley RN, Chen SC, Solid CA, Gilbertson DT, Collins AJ: Early mortality in patients starting dialysis appears to go unregistered. Kidney Int 2014;86:392-398.

64 Maddux D, Usvyat LA, Xu D, Wang Y, Kotanko P, van der Sande FM, et al: The association of weekly pre-hemodialysis systolic blood pressure and following week mortality. Kidney Blood Press Res 2018;43:88-97.

65 RDC T. R: A language and Environment for Statistical Computing. Vienna: R Foundation for Statistical Computing, 2009.

66 Wang Y: Smoothing Splines: Methods and Applications. New York: Champman and Hall, 2011.

67 Kotanko P, Thijssen S, Usvyat L, Tashman A, Kruse A, Huber C, et al: Temporal evolution of clinical parameters before death in dialysis patients: a new concept. Blood Purif 2009;27: 38-47.

68 Thijssen S, Wong MM, Usvyat LA, Xiao Q, Kotanko P, Maddux FW: Nutritional competence and resilience among hemodialysis patients in the setting of dialysis initiation and hospitalization. Clin J Am Soc Nephrol 2015; 10:1593-1601.

69 Usvyat LA, Kooman JP, van der Sande FM, Wang Y, Maddux FW, Levin NW, et al: Dynamics of hospitalizations in hemodialysis patients: results from a large US provider. Nephrol Dial Transplant 2014;29:442-448.

70 Usvyat LA, Barth C, Bayh I, Etter M, von Gersdorff GD, Grassmann A, et al: Interdialytic weight gain, systolic blood pressure, serum albumin, and C-reactive protein levels change in chronic dialysis patients prior to death. Kidney Int 2013;84:149-157.

71 Kotanko P, Kooman J, van der Sande F, Kappel F, Usvyat L: Accelerated or out of control: the final months on dialysis. J Ren Nutr 2014; 24:357-363.

72 Couchoud CG, Beuscart JB, Aldigier JC, Brunet PJ, Moranne OP; REIN registry: Development of a risk stratification algorithm to improve patient-centered care and decision making for incident elderly patients with endstage renal disease. Kidney Int 2015;88:11781186.

73 Cohen LM, Ruthazer R, Moss AH, Germain MJ: Predicting six-month mortality for patients who are on maintenance hemodialysis. Clin J Am Soc Nephrol 2010;5:72-79.

74 Floege J, Gillespie IA, Kronenberg F, Anker SD, Gioni I, Richards S, et al: Development and validation of a predictive mortality risk score from a European hemodialysis cohort. Kidney Int 2015;87:996-1008.

75 Ramspek CL, Voskamp PW, van Ittersum FJ, Krediet RT, Dekker FW, van Diepen M: Prediction models for the mortality risk in chronic dialysis patients: a systematic review and independent external validation study. Clin Epidemiol 2017;9:451-464.
76 Ye X, Dekker MJE, Maddux FW, Kotanko P, Konings C, Raimann JG, et al: Dynamics of nutritional competence in the last year before death in a large cohort of us hemodialysis patients. J Ren Nutr 2017;27:412-420.

77 Streja E, Goldstein L, Soohoo M, Obi Y, Kalantar-Zadeh K, Rhee CM: Modeling longitudinal data and its impact on survival in observational nephrology studies: tools and considerations. Nephrol Dial Transplant 2017; 32(suppl 2):ii77-ii83.

78 Leffondre K, Boucquemont J, Tripepi G, Stel VS, Heinze G, Dunkler D: Analysis of risk factors associated with renal function trajectory over time: a comparison of different statistical approaches. Nephrol Dial Transplant 2015; 30:1237-1243.

79 Tangri N, Inker LA, Hiebert B, Wong J, Naimark $\mathrm{D}$, Kent $\mathrm{D}$, et al: A dynamic predictive model for progression of CKD. Am J Kidney Dis 2017;69:514-520.

80 Greene T, Li L: From static to dynamic risk prediction: time is everything. Am J Kidney Dis 2017;69:492-494.

81 Dekker M, Konings C, Canaud B, Carioni P, Guinsburg A, Madero M, et al: Pre-dialysis fluid status, pre-dialysis systolic blood pressure and outcome in prevalent haemodialysis patients: results of an international cohort study on behalf of the MONDO initiative. Nephrol Dial Transplant 2018, Epub ahead of print.

82 Obermeyer Z, Emanuel EJ: Predicting the future - big data, machine learning, and clinical medicine. N Engl J Med 2016;375:1216-1219.

83 Chen JH, Asch SM: Machine learning and prediction in medicine - beyond the peak of inflated expectations. N Engl J Med 2017;376: 2507-2509.

84 Kasas S, Ruggeri FS, Benadiba C, Maillard C, Stupar P, Tournu H, et al: Detecting nanoscale vibrations as signature of life. Proc Natl Acad Sci U S A 2015;112:378-381.

85 Woods HA, Wilson JK: An information hypothesis for the evolution of homeostasis. Trends Ecol Evol 2013;28:283-289.

86 McEwen BS, Wingfield JC: What is in a name? Integrating homeostasis, allostasis and stress. Horm Behav 2010;57:105-111.

87 Shaffer F, McCraty R, Zerr CL: A healthy heart is not a metronome: an integrative review of the heart's anatomy and heart rate variability. Front Psychol 2014;5:1040.

88 Pittman-Polletta BR, Scheer FA, Butler MP, Shea SA, Hu K: The role of the circadian system in fractal neurophysiological control. Biol Rev Camb Philos Soc 2013;88:873-894.

89 Stadnitski T: Measuring fractality. Front Physiol 2012;3:127.

90 Sejdic E, Lipsitz LA: Necessity of noise in physiology and medicine. Comput Methods Programs Biomed 2013;111:459-470.

91 Waks JW, Tereshchenko LG, Parekh RS: Electrocardiographic predictors of mortality and sudden cardiac death in patients with end stage renal disease on hemodialysis. J Electrocardiol 2016;49:848-854.
92 Oikawa K, Ishihara R, Maeda T, Yamaguchi K, Koike A, Kawaguchi H, et al: Prognostic value of heart rate variability in patients with renal failure on hemodialysis. Int J Cardiol 2009;131:370-377.

93 Suzuki M, Hiroshi T, Aoyama T, Tanaka M, Ishii $\mathrm{H}$, Kisohara $\mathrm{M}$, et al: Nonlinear measures of heart rate variability and mortality risk in hemodialysis patients. Clin J Am Soc Nephrol 2012;7:1454-1460.

94 Hayano J, Takahashi H, Toriyama T, Mukai S, Okada A, Sakata S, et al: Prognostic value of heart rate variability during long-term follow-up in chronic haemodialysis patients with end-stage renal disease. Nephrol Dial Transplant 1999;14:1480-1488.

95 Chen SC, Huang JC, Tsai YC, Hsiu-Chin Mai RN, Jui-Hsin Chen RN, Kuo PL, et al: Heart rate variability change before and after hemodialysis is associated with overall and cardiovascular mortality in hemodialysis. Sci Rep 2016;6:20597.

96 Hur E, Usta M, Toz H, Asci G, Wabel P, Kahvecioglu S, et al: Effect of fluid management guided by bioimpedance spectroscopy on cardiovascular parameters in hemodialysis patients: a randomized controlled trial. Am J Kidney Dis 2013;61:957-965.

97 Ferrario M, Moissl U, Garzotto F, Cruz DN, Tetta C, Signorini MG, et al: The forgotten role of central volume in low frequency oscillations of heart rate variability. PLoS One 2015;10:e0120167.

98 Assimon MM, Flythe JE: Intradialytic blood pressure abnormalities: the highs, the lows and all that lies between. Am J Nephrol 2015; 42:337-350.

99 Assimon MM, Flythe JE: Variability may be the "law of life," but blood pressure variability may forebode a shorter life. Am J Kidney Dis 2016;67:830-833.

100 Flythe JE, Brunelli SM: Blood pressure variability among chronic dialysis patients: recent advances in knowledge. Curr Opin Nephrol Hypertens 2015;24:163-169.

101 Chang TI, Flythe JE, Brunelli SM, Muntner $\mathrm{P}$, Greene T, Cheung AK, et al: Visit-to-visit systolic blood pressure variability and outcomes in hemodialysis. J Hum Hypertens 2014; $28: 18-24$

102 Flythe JE, Inrig JK, Shafi T, Chang TI, Cape $\mathrm{K}$, Dinesh K, et al: Association of intradialytic blood pressure variability with increased all-cause and cardiovascular mortality in patients treated with long-term hemodialysis. Am J Kidney Dis 2013;61: 966-974.

103 Webb AJ, Rothwell PM: Physiological correlates of beat-to-beat, ambulatory, and dayto-day home blood pressure variability after transient ischemic attack or minor stroke. Stroke 2014;45:533-538.

104 Flythe JE, Kunaparaju S, Dinesh K, Cape K, Feldman HI, Brunelli SM: Factors associated with intradialytic systolic blood pressure variability. Am J Kidney Dis 2012;59:409418. 
105 Kato J, Kawagoe Y, Jiang D, Kuwasako K, Shimamoto S, Igarashi K, et al: Plasma levels of natriuretic peptides and year-by-year blood pressure variability: a populationbased study. J Hum Hypertens 2017;31:525529.

106 Raimann JG, Canaud B, Etter M, Kooman JP, Levin NW, Marcelli D, et al: Association between pre hemodialysis serum sodium concentration and blood pressure: results from a retrospective analysis from the international monitoring dialysis outcomes (MONDO) initiative. J Hum Hypertens 2016;30:442448.

107 Kooman JP, Broers NJ, Usvyat L, Thijssen S, van der Sande FM, Cornelis T, et al: Out of control: accelerated aging in uremia. Nephrol Dial Transplant 2013;28:48-54.

108 Scheffer M, Bascompte J, Brock WA, Brovkin V, Carpenter SR, Dakos V, et al: Early-warning signals for critical transitions. Nature 2009;461:53-59.

109 Olde Rikkert MG, Dakos V, Buchman TG, Boer R, Glass L, Cramer AO, et al: Slowing down of recovery as generic risk marker for acute severity transitions in chronic diseases. Crit Care Med 2016;44:601-606.

110 Trefois C, Antony PM, Goncalves J, Skupin A, Balling R: Critical transitions in chronic disease: transferring concepts from ecology to systems medicine. Curr Opin Biotechnol 2015;34:48-55.

111 Gijzel SMW, van de Leemput IA, Scheffer M, Roppolo M, Olde Rikkert MGM, Melis RJF: Dynamical resilience indicators in time series of self-rated health correspond to frailty levels in older adults. J Gerontol A Biol Sci Med Sci 2017;72:991-996.

112 Shiels PG, McGuinness D, Eriksson M, Kooman JP, Stenvinkel P: The role of epigenetics in renal ageing. Nat Rev Nephrol 2017;13:471-482.

113 Kooman JP, Dekker MJ, Usvyat LA, Kotanko P, Van der Sande FM, Schalkwijk CG, et al: Inflammation and premature aging in advanced chronic kidney disease. Am J Physiol Renal Physiol 2017;313:F938F950.

114 Suarez-Alvarez B, Liapis H, Anders HJ: Links between coagulation, inflammation, regeneration, and fibrosis in kidney pathology. Lab Invest 2016;96:378-390.

115 Wiens J, Shenoy ES: Machine learning for healthcare: on the verge of a major shift in healthcare epidemiology. Clin Infect Dis 2018;66:149-153.

116 Pearl J: Interpretation and identification of causal mediation. Psychol Methods 2014;19: 459-481.

117 Goldstein BA, Pomann GM, Winkelmayer WC, Pencina MJ: A comparison of risk prediction methods using repeated observations: an application to electronic health records for hemodialysis. Stat Med 2017;36:2750-2763.

118 Li E, Wang N, Wang NY: Joint models for a primary endpoint and multiple longitudinal covariate processes. Biometrics 2007;63: 1068-1078.

119 Zhao J. Feng Q, Wu P, Lupu R, Wilke RA, Wells QS, Denny JC, Wei QW: Learning from Longitudinal Data in 3 Electronic Health Record and Genetic Data to Improve Cardiovascular Event Prediction. https:// www.biorxiv.org/content/biorxiv/early/2018/07/11/366682.full.pdf. 